\author{
Marquette University \\ e-Publications@Marquette
}

4-2009

\title{
Layered double hydroxides intercalated with borate anions: Fire and thermal properties in ethylene vinyl acetate copolymer
}

Calistor Nyambo

Marquette University

Charles A. Wilkie

Marquette University, charles.wilkie@marquette.edu

Follow this and additional works at: https://epublications.marquette.edu/chem_fac

Part of the Chemistry Commons

\section{Recommended Citation}

Nyambo, Calistor and Wilkie, Charles A., "Layered double hydroxides intercalated with borate anions: Fire and thermal properties in ethylene vinyl acetate copolymer" (2009). Chemistry Faculty Research and Publications. 93.

https://epublications.marquette.edu/chem_fac/93 
Marquette University

\section{e-Publications@Marquette}

\section{Chemistry Faculty Research and Publications/College of Arts and Sciences}

This paper is NOT THE PUBLISHED VERSION; but the author's final, peer-reviewed manuscript. The published version may be accessed by following the link in th citation below.

Polymer Degradation and Stability, Vol. 94, No. 4 (April 2009): 506-512. DOI. This article is (C) Elsevier and permission has been granted for this version to appear in e-Publications@Marquette. Elsevier does not grant permission for this article to be further copied/distributed or hosted elsewhere without the express permission from Elsevier.

\section{Layered Double Hydroxides Intercalated with Borate Anions: Fire and Thermal Properties in Ethylene Vinyl Acetate Copolymer}

Calistor Nyambo

Department of Chemistry and Fire Retardant Research Facility, Marquette University, Milwaukee, WI Charles A. Wilkie Department of Chemistry and Fire Retardant Research Facility, Marquette University, Milwaukee, WI

\section{Abstract}

Fire and thermal properties of ethylene vinyl acetate (EVA) composites prepared by melt blending with layered double hydroxides (LDH) have been studied. Two types of LDHs intercalated with borate anion were prepared using the coprecipitation method and the metals $\mathrm{Mg}^{2+}, \mathrm{Zn}^{2+}$ and $\mathrm{Al}^{3+}$. Characterization of the LDHs and the EVA composites was performed using $\mathrm{X}$-ray diffraction, thermogravimetric analysis, and cone calorimetry. Thermal analyses show that the addition of LDHs improves the thermal stability of EVA. Fire properties evaluated using the cone calorimeter were significantly improved in the EVA/LDH composites. The peak heat release rate was reduced by about $40 \%$ when only $3 \%$ by weight of the $\mathrm{LDH}$ was added to the copolymer. Comparison of the fire properties of the LDHs with those of aluminum trihydrate (ATH), magnesium hydroxides (MDH), zinc hydroxide $(\mathrm{ZH})$ and their combinations at $40 \%$ loading, reveal that the LDHs were more effective than when $\mathrm{MDH}$ and $\mathrm{ZH}$ are used alone. 


\section{Keywords}

Ethylene vinyl acetate, Layered double hydroxide, Borate, Thermogravimetry, Fire retardancy, Cone calorimeter

\section{Introduction}

Fire retarded ethylene vinyl acetate (EVA) copolymer is used worldwide as an insulator for wires and cables. Since pristine EVA is easily flammable, it is not suitable for many applications and in most cases halogencontaining flame retardants (FRs) or the minerals alumina trihydrate (ATH) and magnesium hydroxide (MDH) are used as flame retardants (FRs) for this copolymer [1], [2], [3], [4], [5], [6]. These FRs have some major shortcomings, for example, the pyrolysis products from halogenated FRs are considered corrosive and toxic while the fillers ATH and $\mathrm{MDH}$ are only effective at high loadings, greater than $60 \%$, which is often detrimental to mechanical properties. Efforts are directed to find FRs that are effective at lower loadings and are also environmentally friendly. Layered double hydroxides (LDHs) have emerged as promising FRs because they have been shown to improve thermal stability and fire retardancy [7], [8], [9].

$\mathrm{LDH}$ s are anionic clays that are both synthetic and naturally occurring. The general formula for LDHs is $\left.\left[\mathrm{M}^{2+}{ }_{1-x} \mathrm{M}^{3+}{ }_{x} \cdot(\mathrm{OH})_{2}\right]^{x+}\left(\mathrm{A}_{x / n}\right)^{n-} \cdot m \mathrm{H}_{2} \mathrm{O}\right]$, where $\mathrm{M}^{2+}=$ divalent cation $\left(\mathrm{Mg}^{2+}, \mathrm{Zn}^{2+}, \mathrm{Co}^{2+}\right), \mathrm{M}^{3+}=$ trivalent cation $\left(\mathrm{Al}^{3+}, \mathrm{Fe}^{3+}\right.$, $\mathrm{Mn}^{3+}$ ) and $\mathrm{A}^{n-}$ is the charge balancing interlayer anion. In simple terms the structure of LDHs can be derived from that of brucite, $\mathrm{Mg}(\mathrm{OH})_{2}$, which is composed of edge-sharing $\mathrm{Mg}(\mathrm{OH})_{6}$ Octahedral sheets $\frac{10]}{10}$. Partial substitution of the $\mathrm{Mg}^{2+}$ with $\mathrm{Al}^{3+}$ creates a positive charge on the metal layers. This positive charge is then counter balanced by the presence of anions in the galleries. The charge balancing anions can be organic or inorganic and common examples are alkyl carboxylates, carbonate, nitrate, etc. Since both the composition of the metal layers and the gallery anions can be varied, there is enormous potential for preparing LDHs with a wide range of applications including use as flame retardants. In related work, many investigations have demonstrated that borates improve fire retardancy [11], [12], [13], [14]. Melamine borate, ammonium pentaborate and zinc borate are some examples of commonly used boron-containing commercial FRs; the introduction of borate anion into the galleries of LDHs may improve fire retardancy. Furthermore, $\mathrm{LDHs}$ prepared with $\mathrm{Mg}^{2+}$ and $\mathrm{Al}^{3+}$ possess compositions similar to those of $\mathrm{MDH}$ and $\mathrm{ATH}$, while a combination of $\mathrm{Zn}^{2+}, \mathrm{Al}^{3+}$ and borate anion in $\mathrm{LDH}$ resemble zinc borate (ZB) and ATH.

The purpose of this study is to develop flame retardant LDHs intercalated with borate anion to be used in EVA. Comparing the fire performance effectiveness of the LDHs containing different types of metals $\mathrm{Mg}^{2+} / \mathrm{Al}^{3+}$ and $\mathrm{Zn}^{2+} / \mathrm{Al}^{3+}$ together with commercial FRs, such as melamine polyphosphate (MP), zinc borate (ZB), $\mathrm{ATH}$ and $\mathrm{MDH}$ and their combinations, is another objective of the work.

\section{Experimental}

\subsection{Materials}

The materials used were zinc nitrate, sodium hydroxide flakes, magnesium nitrate hexahydrate, $\mathrm{Mg}\left(\mathrm{NO}_{3}\right)_{2} \cdot 6 \mathrm{H}_{2} \mathrm{O}$, aluminum nitrate nonahydrate, $\mathrm{Al}\left(\mathrm{NO}_{3}\right)_{3} \cdot 9 \mathrm{H}_{2} \mathrm{O}$ from Aldrich Chemical Co, ethylene vinyl acetate copolymer (EVA) (Escorene Ultra from Exxon Mobil Chemical), zinc hydroxide (ZH) (City chemical), zinc borate (Fire Brake 415) and boric acid from Rio Tinto Inc; melamine polyphosphate (melapur 200/70 from Ciba Specialty Chemicals), magnesium hydroxide (MDH) (magnifin $\mathrm{H} 7-\mathrm{C}$ ) and alumina trihydrate (ATH) (martinal char 42) (Albemarle Corp). All chemicals were used without further purification.

\subsection{Instrumentation}

Powder X-ray diffraction measurements (PXRD) and XRD for the composites were performed in a Rigaku, Miniflex II Desktop, X-ray diffractometer with a Cu (K alpha) source $\lambda=1.54078 \AA$, from a sealed X-ray tube. The powder samples were prepared and mounted on a glass holder while thin plaques of composites were fabricated via compression molding and mounted on an aluminum sample. The data were collected at various $2 \vartheta$ values from 0 to $70^{\circ}$ at a scan speed of $5^{\circ}$ per minute with a sampling width of 0.02 .

Thermogravimetric analysis (TGA) and differential thermal analysis (DTA) were performed on an SDT 2960 simultaneous DTA-TGA instrument from 50 to $800^{\circ} \mathrm{C}$ at a heating rate of $20^{\circ} \mathrm{C} / \mathrm{min}$ in $\mathrm{N}_{2}$, flowing at 
$85 \pm 5 \mathrm{ml} / \mathrm{min}$, with sample sizes of $15.0 \pm 1.0 \mathrm{mg}$ contained in aluminum sample cups. All samples were run in triplicate and average values are reported; temperatures are considered accurate to $\pm 3{ }^{\circ} \mathrm{C}$ and the error on the fraction of non-volatile materials is $\pm 2 \%$. Approximately $30 \mathrm{~g}$ of EVA composite samples were compression molded into $10 \mathrm{~cm} \times 10 \mathrm{~cm}$ square plaques of uniform thickness $(\sim 3 \mathrm{~mm})$ before cone calorimetry was performed on an Atlas Cone 2 instrument at an incident flux of $35 \mathrm{~kW} / \mathrm{m}^{2}$ with a cone shaped heater; the spark was continuous until the sample ignited. All samples were run in triplicate and the average value, with standard deviation, is reported; results from cone calorimeter are generally considered to be reproducible to $\pm 10 \%$.

\subsection{Preparation of the $\mathrm{Mg} / \mathrm{Zn} \mathrm{Al}$-borate layered double hydroxides}

The LDHs were synthesized by the coprecipitation method, following a procedure similar to that reported by Bhattacharyya and Hall ${ }^{[15]}$. The preparation was performed in a nitrogen atmosphere to exclude $\mathrm{CO}_{2}$, whose presence would lead to the incorporation of carbonate in the LDHs. In a typical preparation of the magnesium aluminum borate layered double hydroxide (MgAl-borate LDH), a solution of $38.5 \mathrm{~g}$ of $\mathrm{Mg}\left(\mathrm{NO}_{3}\right)_{2} \cdot 6 \mathrm{H}_{2} \mathrm{O}(0.150 \mathrm{~mol})$ and $28.1 \mathrm{~g}$ of $\mathrm{Al}\left(\mathrm{NO}_{3}\right)_{3} \cdot 9 \mathrm{H}_{2} \mathrm{O}(0.0750 \mathrm{~mol})$ in $200 \mathrm{ml}$ of degassed and deionized water was added dropwise over $1 \mathrm{~h}$ to a solution of $20.9 \mathrm{~g}$ of $\mathrm{H}_{3} \mathrm{BO}_{3}(0.338 \mathrm{~mol})$ in $200 \mathrm{ml}$ of degassed/deionized water. The $\mathrm{pH}$ of the solution was maintained at 9.0 by adding $1 \mathrm{M} \mathrm{NaOH}$ solution as needed. The resulting white precipitate was aged for $24 \mathrm{~h}$ at $65^{\circ} \mathrm{C}$, and then filtered until all of the supernatant liquid was removed. The sample was washed several times with large amounts of deionized and degassed water, and dried at $50^{\circ} \mathrm{C}$ in a vacuum oven. The same procedure was repeated for preparation of the zinc aluminum borate layered double hydroxide (ZnAl-borate LDH), with the exception that the pH was maintained at 8.3.

\subsection{Preparation of the ethylene vinyl acetate composites}

Ethylene vinyl acetate-LDH composites were prepared via melt blending using established methods $\underline{[16]}$. Melt blending was chosen because it is a solvent-free, convenient and environmentally friendly method. The composites were prepared on a Brabender mixer (temperature $=120^{\circ} \mathrm{C}$, screw speed $=60 \mathrm{rpm}$, and time $=8 \mathrm{~min}$ ). Constitutive proportions of LDH samples are presented in Table 1. . A reference sample of unmodified ethylene vinyl acetate was obtained by following the same procedure without any additive.

Table 1. Composition of ethylene vinyl acetate composites.

\begin{tabular}{|l|l|l|l|l|l|l|l|}
\hline Formulation & EVA & LDH & MDH & ATH & ZH & ZB & MP \\
\hline EVA & 100 & 0 & 0 & 0 & 0 & 0 & 0 \\
\hline +3\%LDH & 97 & 3 & 0 & 0 & 0 & 0 & 0 \\
\hline +5\%LDH & 95 & 5 & 0 & 0 & 0 & 0 & 0 \\
\hline +10\%LDH & 90 & 10 & 0 & 0 & 0 & 0 & 0 \\
\hline +20\%LDH & 80 & 20 & 0 & 0 & 0 & 0 & 0 \\
\hline +40\%LDH & 60 & 40 & 0 & 0 & 0 & 0 & 0 \\
\hline +40\%MDH & 60 & 0 & 40 & 0 & 0 & 0 & 0 \\
\hline +40\%ATH & 60 & 0 & 0 & 40 & 0 & 0 & 0 \\
\hline +40\%ZH & 60 & 0 & 0 & 0 & 40 & 0 & 0 \\
\hline +40\%ZB & 60 & 0 & 0 & 0 & 0 & 40 & 0 \\
\hline +40\% (2:1 MDH:ATH) & 60 & 0 & 27.7 & 13.3 & 0 & 0 & 0 \\
\hline +40\% (2:1 ZH:ATH) & 60 & 0 & 0 & 13.3 & 27.3 & 0 & 0 \\
\hline +10\%MP & 90 & 0 & 0 & 0 & 0 & 0 & 10 \\
\hline +7\%MP + 3\%LDH & 90 & 3 & 0 & 0 & 0 & 0 & 7 \\
\hline +5\%MP + 5\%LDH & 90 & 5 & 0 & 0 & 0 & 0 & 5 \\
\hline +3\%MP + 7\%LDH & 90 & 7 & 0 & 0 & 0 & 0 & 3 \\
\hline +10\%LDH & 90 & 10 & 0 & 0 & 0 & 0 & 0 \\
\hline
\end{tabular}

EVA, ethylene vinyl acetate; LDH, layered double hydroxide which is either MgAl-borate or ZnAl-borate; MDH; magnesium hydroxide; $\mathrm{ATH}$, aluminum trihydrate; $\mathrm{ZH}$, zinc hydroxide; $\mathrm{ZB}$, zinc borate (Fire Brake 415); and MP, melamine polyphosphate, $\mathrm{Zn}$ Al-borate LDH was used in combination with MP. 


\section{Results and discussion}

\subsection{Characterization of $\mathrm{Mg} / \mathrm{Zn}-\mathrm{Al} \mathrm{LDHs}$ and their ethylene vinyl acetate composites}

\subsubsection{X-ray diffraction (XRD) analysis}

Fig. 1 gives a comparison of the XRD traces for the LDHs. Three equidistant peaks are observed in the two types of LDHs and these reveal good crystallinity and confirm the presence of borate anion in the galleries of the LDH. The $2 \vartheta$ values for the $\mathrm{ZnAl}$-borate $\left(8.2^{\circ}\right)$ and $\mathrm{MgAl}$-borate $\mathrm{LDHs}\left(8.3^{\circ}\right)$ correspond to $d$-spacings of 10.8 and $10.5 \AA$ respectively, using the Bragg equation. Subtracting $4.6 \AA$, the thickness of a brucite layer gives interlayer spacings of $6.2 \AA$ and $5.9 \AA$ for ZnAl-borate and MgAl-borate LDHs respectively and these are not significantly different. The XRD data for these LDHs agree very well with those reported in the literature [15], [17], [18]. Fig. 2 presents the XRD traces of the EVA composites containing Zn/MgAl-borate LDHs. No diffraction peaks were observed in the XRD traces of the EVA composites. Based on previous work on nanocomposites [19], [20], the observed $d$-spacings of the $\mathrm{Zn} / \mathrm{MgAl}$-borate LDHs, which are smaller than those of unmodified montmorillonite ( $d$-spacing of $11.7 \AA$ ), are too small to permit entry of the polymer. The absence of diffraction peaks in the XRD patterns of the composites must be due to disordering of the LDHs and these systems are microcomposites, in other words, the borate LDHs are acting as conventional fillers.

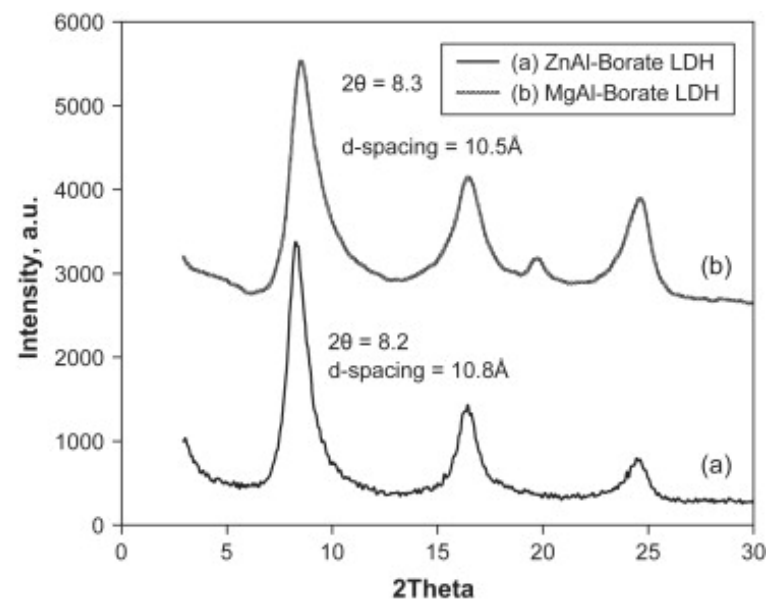

Fig. 1. Powder XRD patterns of $\mathrm{Mg} / \mathrm{ZnAl}-$ borate LDHs.

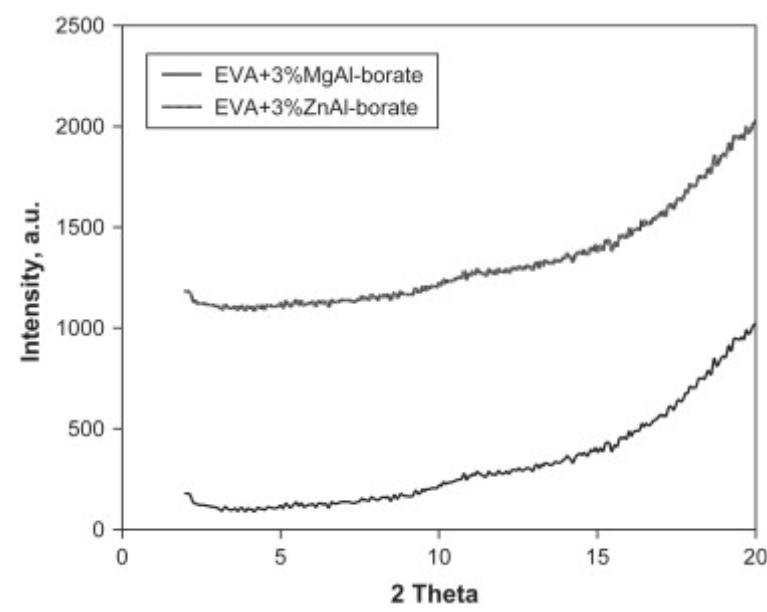

Fig. 2. XRD traces of EVA + MgAl-borate LDHs.

\subsection{Thermal stability of the $\mathrm{Mg} / \mathrm{Zn}-\mathrm{Al} \mathrm{LDH}$ and their ethylene vinyl acetate composites}

Thermogravimetric analysis (TGA) is the tool of choice for characterizing the thermal stability of polymers and fire retardants. The most important parameters used for comparing thermal stability are the onset 
degradation temperature, $T_{0.1}$, (temperature at $10 \%$ mass loss), the mid-point temperature, $T_{0.5}$ (the temperature at $50 \%$ mass loss) and the residue at $600^{\circ} \mathrm{C}$. TGA and differential thermal gravimetry (DTG) curves of the $\mathrm{Zn} / \mathrm{Mg}-\mathrm{Al}$ borate LDHs are shown in Fig. 3 and the data are summarized in the inset in Fig. $3(\mathrm{a})$. Thermal degradation of LDHs is generally characterized by: (i) the loss of adsorbed water $\left(0-150{ }^{\circ} \mathrm{C}\right.$ ), and (ii) interlayer water $150-250^{\circ} \mathrm{C}$ followed by (iii) dehydroxylation $\left(250^{\circ} \mathrm{C}\right.$ ) and (iv) decomposition of the gallery anions [21], [22], [23], [24], [25]. The first two steps are observed in the thermal degradation of these borate LDHs while the dehydroxylation step overlaps with the decomposition of the anion. There is no difference in the TGAs of the two LDHs, except for the amount of residual material at $600^{\circ} \mathrm{C}$. The data in the inset in Fig. 3(a), show that ZnAlborate gives a residue of $75 \%$ while the $\mathrm{MgAl}$-borate gives about $67 \%$ and this is reasonable since $\mathrm{Zn}$ is heavier than $\mathrm{Mg}$.
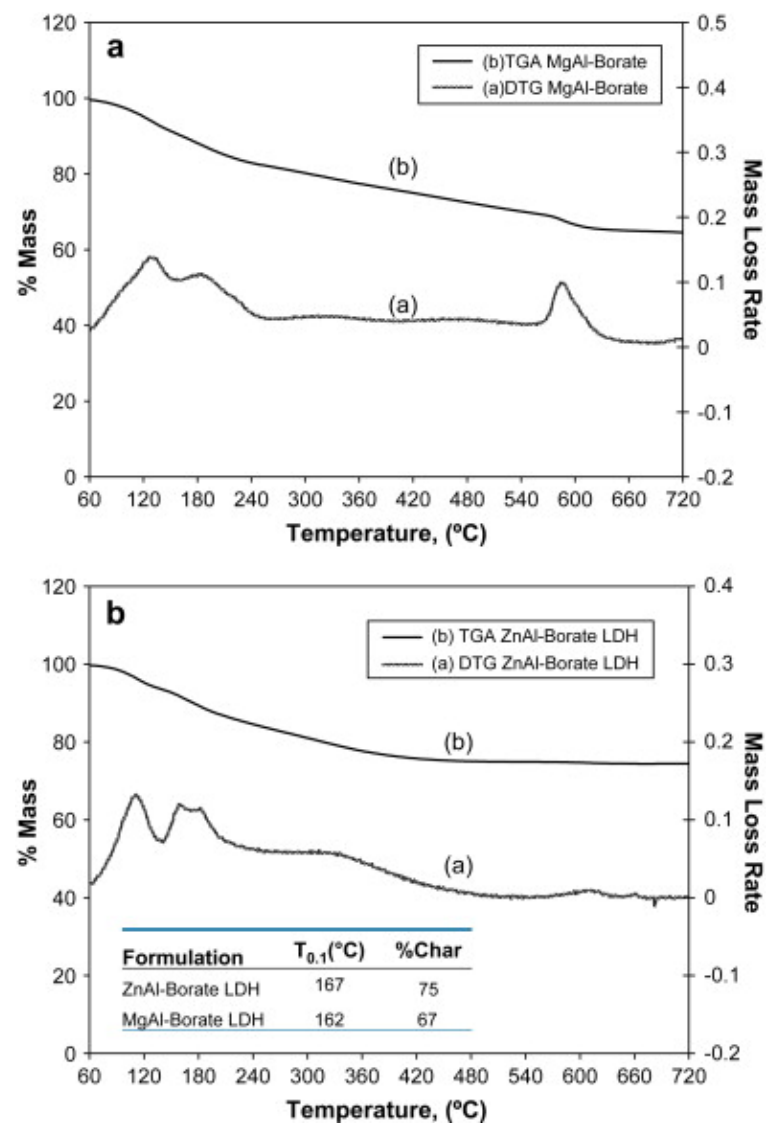

Fig. 3. TGA and DTG curves for (a) MgAl-borate LDH and (b) ZnAl-borate LDHs.

Thermal degradation of EVA in air has been studied extensively and is known to proceed by a three-step process [26], [27], [28], [29]. The first step $\left(250-400^{\circ} \mathrm{C}\right)$ is due to the loss of acetic acid from the decomposition of the vinyl acetate group, while the second $\operatorname{step}\left(400-500{ }^{\circ} \mathrm{C}\right)$ is assigned to the degradation of the unsaturated polyethylenic chains. Decomposition of the carbonaceous char occurs as the last step $\left(500-600{ }^{\circ} \mathrm{C}\right)$. These steps have been assigned and are all clearly shown in the TGA and DTG plots presented in Fig. 4(a) and (b). TGA plots show that the addition of the MgAl-borate LDH and ZnAl-borate LDHs to EVA improves the thermal stability and does not seem to affect the degradation steps of the copolymer. From the TGA data summarized in Table 2, the thermal stability, as measured by $T_{0.5}$, increases with an increase in the loading of the LDHs. The best thermal stability effect is obtained at $40 \%$ loading of the $L D H$, and this is comparable to that obtained in composites with zinc borate and MDH alone and combinations of MDH and ATH. Both ATH and zinc hydroxide alone at $40 \%$ loading improves the $T_{0.5}$ more than the LDH does. As would be expected the char obtained at $600{ }^{\circ} \mathrm{C}$ increases with an increase in loading of the LDHs and show no significant differences between the two types of LDHs. There is no significant difference of the char obtained at $40 \%$ loading of the additives and their combinations. 

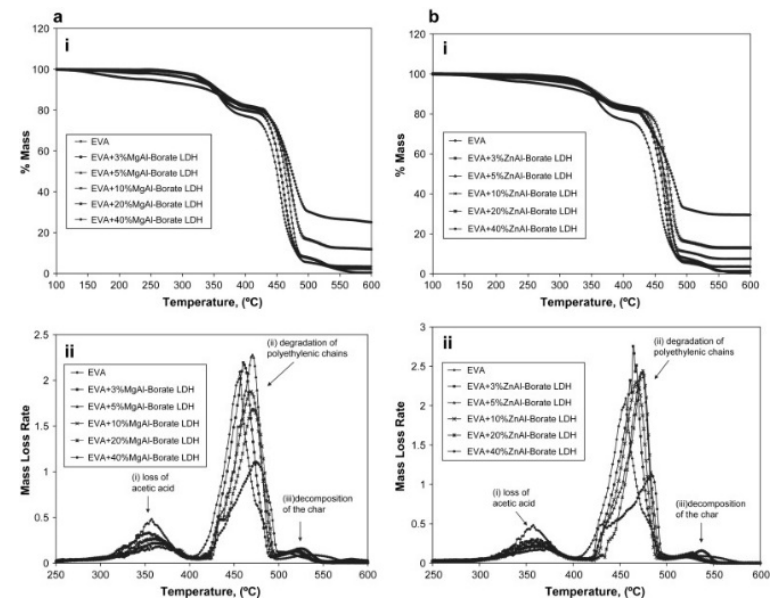

Fig. 4. (a) TGA curves for (i) EVA + MgAl-borate LDHs and (ii) DTG curves for EVA + MgAl-borate LDH. (b) TGA curves for (i) EVA + ZnAl-borate LDHs and DTG curves for (ii) EVA + ZnAl-borate LDH.

Table 2. TGA data for ethylene vinyl acetate and its composites.

\begin{tabular}{|l|l|l|l|l|l|}
\hline Formulation & $\boldsymbol{T}_{\mathbf{0 . 1}}\left({ }^{\circ} \mathbf{C}\right)$ & $\boldsymbol{T}_{0.5}\left({ }^{\circ} \mathbf{C}\right)$ & $\%$ Char & $\Delta T_{0.5}$ & $\Delta T_{0.1}$ \\
\hline EVA & 350 & 449 & 0 & & \\
\hline EVA + 3\%MgAl-borate LDH & 350 & 456 & 2 & 7 & 0 \\
\hline EVA + 5\%MgAl-borate LDH & 354 & 462 & 3 & 13 & 4 \\
\hline EVA + 10\%MgAl-borate LDH & 352 & 463 & 6 & 14 & 2 \\
\hline EVA + 20\%MgAl-borate LDH & 354 & 466 & 12 & 17 & 4 \\
\hline EVA + 40\%MgAl-borate LDH & 340 & 473 & 25 & 24 & -10 \\
\hline EVA + 3\%ZnAl-borate LDH & 357 & 460 & 1 & 11 & 7 \\
\hline EVA + 5\%ZnAl-borate LDH & 353 & 464 & 4 & 15 & 3 \\
\hline EVA + 10\%ZnAl-borate LDH & 362 & 463 & 8 & 14 & 12 \\
\hline EVA + 20\%ZnAl-borate LDH & 356 & 470 & 13 & 21 & 6 \\
\hline EVA + 40\%ZnAl-borate LDH & 344 & 476 & 30 & 27 & -6 \\
\hline EVA + 40\%MDH & 359 & 477 & 28 & 28 & 9 \\
\hline EVA + 40\%ATH & 327 & 489 & 26 & 40 & -23 \\
\hline EVA + 40\% (2:1 MH:ATH) & 357 & 479 & 27 & 30 & 7 \\
\hline EVA + 40\% (2:1 ZH:ATH) & 353 & 480 & 32 & 31 & 3 \\
\hline EVA + 40\%ZH & 377 & 491 & 35 & 42 & 27 \\
\hline EVA + 40\%Zinc borate & 372 & 473 & 34 & 24 & 22 \\
\hline EVA + 7\%ZnAl-borate LDH + 3\%MP & 364 & 460 & 6 & 11 & 14 \\
\hline EVA + 5\%ZnAl-borate LDH + 5\%MP & 365 & 459 & 5 & 10 & 15 \\
\hline EVA + 3\%ZnAl-borate LDH + 7\%MP & 357 & 460 & 5 & 11 & 7 \\
\hline EVA + 10\%MP & 362 & 463 & 8 & 14 & 12 \\
\hline
\end{tabular}

$T_{0.1}$, temperature at which $10 \%$ mass loss occurs; $T_{0.5}$, temperature at which $50 \%$ mass loss occurs; $\%$ Char, residue at $600{ }^{\circ} \mathrm{C}$; $\Delta T_{0.5}, T_{0.5}$ (composites) minus $T_{0.5}$ (neat PMMA); $\Delta T_{0.1}, T_{0.1}$ (composites) minus $T_{0.1}$ (neat PMMA).

\subsection{Flammability behavior of the ethylene vinyl acetate composites}

Cone calorimetry is the most important tool for assessing flammability behavior of polymer composites. This provides the heat release rate (HRR), and especially its peak value (PHRR); total heat released (THR); volume of smoke released (VOS); average mass loss rate (AMLR); time to ignition ( $\left.t_{\text {ig }}\right)$; and the char yield. The cone calorimetry data are summarized in Table 3a, Table 3b, and the plots of heat release rate versus time are shown in Fig. 5. To compare the effectiveness of flame retardants in composites, the reduction in the peak heat release (PHRR) is the most important parameter obtained from cone calorimetry and this gives a general indication on the size of the fire and how fast it grows. The addition of the LDHs reduces the PHRR of the composites 
significantly, as shown in Fig. 5. At loadings of about 3\% MgAl-borate LDH and 3\% ZnAl-borate the PHRR is reduced by $42 \%$ and $36 \%$, respectively. As the loadings of LDH increase from 3 to $40 \%$ the reduction in PHRR also increase. There is no significant difference in the PHRR reduction for the $\mathrm{ZnAl}$-borate and MgAl-borate LDHs. At $40 \%$ loading the fire performance of $\mathrm{LDH}$ s is better than that of $\mathrm{MDH}$ or $\mathrm{ZH}$ alone, but not as good as that obtained for ATH and ZB alone. The best reduction in PHRR at $40 \%$ additive loading is $89 \%$, and this is observed with both ATH and zinc borate. The LDHs gives reductions in PHRR that are significantly larger than those observed when 2:1 a combination of ZH/ATH is used but similar to that of composites with the combination of $\mathrm{MDH} / \mathrm{ATH}$. The observed reduction in total heat released (THR), especially at high loading of 20 and $40 \%$, may simply be explained by the reduction in the amount of fuel due to partial replacement of the EVA by the LDH. Addition of the LDH increases the VOS, but at $40 \%$ loadings there is no significant difference in the smoke produced (VOS) for all the additives. The AMLR decreases with an increase in the LDH loading and correlates with the reduction in PHRR. The smallest values of AMLR are obtained when ATH and zinc borate are used and these also give the best reduction in PHRR. The time to ignition is also reduced by the addition of the LDHs while the char yield increases with the loading of the LDHs. The fire retardant action of the borate intercalated LDHs may be explained by their endothermic decomposition that results in the formation of water vapor and mixed metal oxide residue. The oxides are important for fire retardancy because they reduce the flaming process by acting as a barrier that protects the polymer surface and suppress the rate of fuel supply to the flaming area [30], [31].

Table 3a. Cone calorimetry data for ethylene vinyl acetate composites at $35 \mathrm{~kW} / \mathrm{m}^{2}$.

\begin{tabular}{|c|c|c|c|c|c|c|c|}
\hline Formulation & $\begin{array}{l}\text { PHRR } \\
\left(\mathrm{kW} / \mathrm{m}^{2}\right)\end{array}$ & $\begin{array}{l}\text { Rdctn } \\
\text { (\%) }\end{array}$ & $\begin{array}{l}\text { THR } \\
\left(\mathrm{MJ} / \mathrm{m}^{2}\right)\end{array}$ & VOS (I) & $\begin{array}{l}\text { AMLR } \\
\left(\mathrm{g} / \mathrm{s} \mathrm{m}^{2}\right)\end{array}$ & $t_{\text {ig }}(s)$ & $\begin{array}{l}\text { Char } \\
\text { (\%) }\end{array}$ \\
\hline EVA & $2027 \pm 137$ & NA & $118 \pm 7$ & $516 \pm 101$ & $48 \pm 7$ & $58 \pm 4$ & $0 \pm 0$ \\
\hline EVA + 3\%MgAl-borate LDH & $1169 \pm 77$ & 42 & $110 \pm 9$ & $1013 \pm 109$ & $34 \pm 1$ & $35 \pm 1$ & $2 \pm 0$ \\
\hline EVA + 5\%MgAl-borate LDH & $1146 \pm 109$ & 43 & $111 \pm 7$ & $1350 \pm 322$ & $36 \pm 2$ & $36 \pm 1$ & $3 \pm 1$ \\
\hline EVA + 10\%MgAl-borate LDH & $1031 \pm 58$ & 49 & $111 \pm 2$ & $1160 \pm 131$ & $34 \pm 1$ & $36 \pm 2$ & $6 \pm 0$ \\
\hline 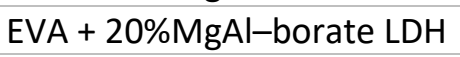 & $919 \pm 144$ & 55 & $99 \pm 2$ & $1296 \pm 133$ & $32 \pm 1$ & $40 \pm 2$ & $13 \pm 1$ \\
\hline 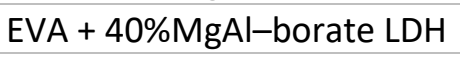 & $530 \pm 51$ & 74 & $77 \pm 1$ & $901 \pm 73$ & $15 \pm 1$ & $43 \pm 1$ & $26 \pm 0$ \\
\hline EVA + 3\%ZnAl-borate LDH & $1287 \pm 15$ & 36 & $116 \pm 1$ & $1226 \pm 89$ & $36 \pm 4$ & $48 \pm 3$ & $3 \pm 0$ \\
\hline EVA + 5\%ZnAl-borate LDH & $867 \pm 52$ & 57 & $117 \pm 1$ & $1013 \pm 47$ & $30 \pm 2$ & $51 \pm 5$ & $4 \pm 0$ \\
\hline EVA + 10\%ZnAl-borate LDH & $750 \pm 35$ & 63 & $111 \pm 1$ & $1267 \pm 63$ & $27 \pm 3$ & $53 \pm 6$ & $9 \pm 1$ \\
\hline EVA + 20\%ZnAl-borate LDH & $834 \pm 15$ & 59 & $102 \pm 2$ & $721 \pm 161$ & $28 \pm 4$ & $38 \pm 2$ & $14 \pm 1$ \\
\hline EVA + 40\%ZnAl-borate LDH & $460 \pm 23$ & 77 & $77 \pm 2$ & $898 \pm 77$ & $16 \pm 4$ & $51 \pm 4$ & $30 \pm 1$ \\
\hline $\mathrm{EVA}+40 \% \mathrm{MDH}$ & $703 \pm 95$ & 65 & $75 \pm 2$ & $687 \pm 52$ & $22 \pm 3$ & $63 \pm 3$ & $29 \pm 1$ \\
\hline EVA + 40\%ATH & $222 \pm 29$ & 89 & $74 \pm 1$ & $743 \pm 136$ & $9 \pm 1$ & $54 \pm 5$ & $31 \pm 1$ \\
\hline$E V A+40 \% Z H$ & $1079 \pm 106$ & 47 & $52 \pm 5$ & $910 \pm 62$ & $27 \pm 3$ & $36 \pm 4$ & $34 \pm 1$ \\
\hline EVA $+40 \%$ Zinc borate & $231 \pm 9$ & 89 & $81 \pm 1$ & $835 \pm 144$ & $5 \pm 1$ & $50 \pm 3$ & $36 \pm 1$ \\
\hline EVA + 40\% (2:1 MDH:ATH) & $577 \pm 23$ & 72 & $75 \pm 1$ & $692 \pm 136$ & $22 \pm 1$ & $63 \pm 2$ & $32 \pm 1$ \\
\hline EVA + 40\% (2:1 ZH:ATH) & $1052 \pm 146$ & 48 & $73 \pm 3$ & $625 \pm 40$ & $33 \pm 4$ & $44 \pm 5$ & $30 \pm 1$ \\
\hline
\end{tabular}

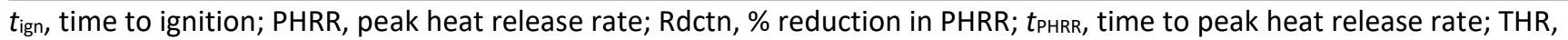
total heat release; VOS, volume of smoke released; AMLR, average mass loss rate.

Table 3b. Cone calorimetry data for composites of ethylene vinyl acetate with melamine polyphosphate (MP) obtained at $35 \mathrm{~kW} / \mathrm{m}^{2}$.

\begin{tabular}{|c|c|c|c|c|c|c|}
\hline Formulation & $\begin{array}{l}\text { PHRR } \\
\left(\mathrm{kW} / \mathrm{m}^{2}\right)\end{array}$ & Rdctn (\%) & $\begin{array}{l}\text { THR } \\
\left(\mathrm{MJ} / \mathrm{m}^{2}\right)\end{array}$ & $\operatorname{vos}(1)$ & $\begin{array}{l}\text { AMLR } \\
\left(\mathrm{g} /\left(\mathrm{s} \mathrm{m}^{2}\right)\right)\end{array}$ & $t_{\mathrm{ig}}(\mathrm{s})$ \\
\hline EVA & $1709 \pm 213$ & NA & $121 \pm 5$ & $1044 \pm 133$ & $22 \pm 4$ & $61 \pm 6$ \\
\hline EVA + 10\%ZnAl-borate LDH & $642 \pm 53$ & 62 & $112 \pm 3$ & $1094 \pm 11$ & $21 \pm 2$ & $43 \pm 1$ \\
\hline EVA + 7\%ZnAl-borate + 3\%MP & $804 \pm 55$ & 53 & $111 \pm 1$ & $736 \pm 36$ & $22 \pm 8$ & $40 \pm 5$ \\
\hline EVA + 5\%ZnAl-borate + 5\%MP & $731 \pm 34$ & 57 & $113 \pm 1$ & $1158 \pm 257$ & $17 \pm 1$ & $38 \pm 5$ \\
\hline
\end{tabular}




\begin{tabular}{|l|l|l|l|l|l|l|}
\hline EVA $+3 \%$ ZnAl-borate $+7 \% \mathrm{MP}$ & $806 \pm 81$ & 53 & $133 \pm 19$ & $978 \pm 146$ & $15 \pm 1$ & $36 \pm 6$ \\
\hline EVA $+10 \% \mathrm{MP}$ & $689 \pm 47$ & 60 & $113 \pm 1$ & $1227 \pm 292$ & $14 \pm 3$ & $48 \pm 8$ \\
\hline
\end{tabular}

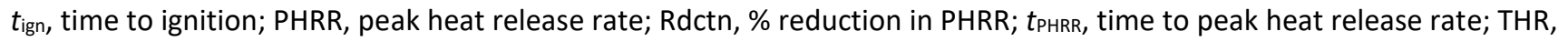
total heat release; AMLR, average mass loss rate.
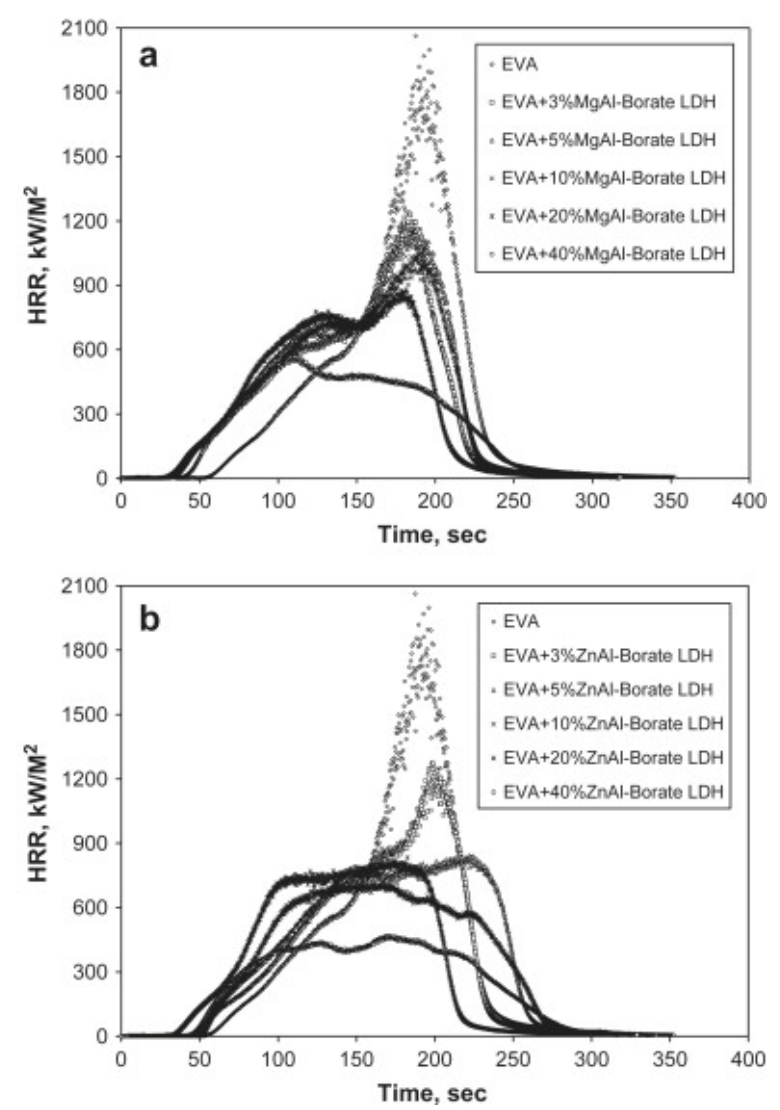

Fig. 5. Heat release rate curves for (a) EVA + MgAl-borate LDH, (b) EVA + ZnAl-borate LDH, and (c) EVA + control additives.

The cone calorimetry data for EVA composites containing ZnAl-borate LDH, MP and their combinations are presented in Table 3b. The addition of either $10 \%$ of melamine polyphosphate (MP) or 10\% ZnAl-borate LDH gives similar fire performance. Combining MP and ZnAl-borate LDH a total additive loading of $10 \%$ gives the same result i.e. the combination is no more effective than an individual component; there is no synergistic interaction.

The formation of powder-like material in some of the composites was observed after cone calorimetry and the photographs of the char are shown in Fig. 6 . The appearance of the char was different depending on the additive used. The chars obtained from ZnAl-borate, zinc borate and zinc hydroxide were hard while those from MgAl-borate, MDH, ATHT and combination of MDH with ATH were soft and powdery. XRD traces for the char after cone calorimetry are shown in Fig. 7(i). XRD analyses show that the char from the LDH composites was amorphous and could not be indexed due to its poor crystallinity. Attempts to calcine the char at $1000{ }^{\circ} \mathrm{C}$ from LDHs resulted in the formation of glassy material that bonded strongly with the ceramic cup holder and could not be isolated for further XRD analyses. With the char obtained from zinc hydroxide and its combination with ATH, diffraction peaks were observed and these matched those of zinc oxide ${ }^{[32]}$ as presented in Fig. 7(ii). The cone calorimetry results obtained at $3 \%$ loading of the borate LDHs are consistent to those reported in previous work $\frac{[33]}{3}$, in which an LDH modified with 2-aminotoluene-5-sulfonate was melt blended with EVA at 3\% loading and 39\% reduction in PHRR was observed. They are also comparable to those observed for EVA composites containing MMT modified with a ferrocenium cation ${ }^{[34]}$. 

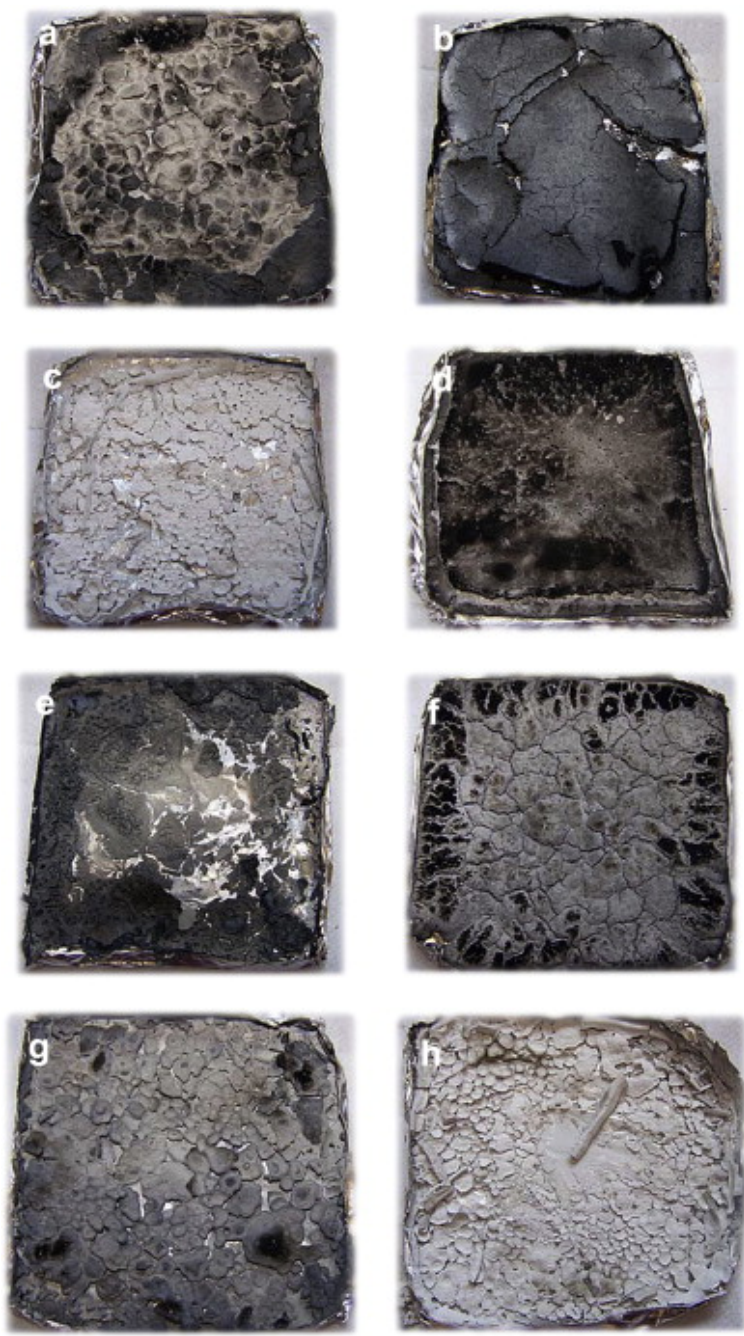

Fig. 6. Photographs of residual char from (a) EVA + 40\% MgAl-borate LDH, (b) EVA + 40\% ZnAl-borate LDH, (c) $E V A+40 \% \mathrm{ZH}$, (d) EVA + 40\% ZB, (e) EVA + 40\% ZH, (f) EVA + 40\%ATH, (g) EVA + 40\% (2:1 MDH:ATH), and (h) $\mathrm{EVA}+40 \%(2: 1 \mathrm{ZH}: \mathrm{ATH})$ formulations following cone calorimetry test under a heat flux of $35 \mathrm{~kW} / \mathrm{m}^{2}$. 

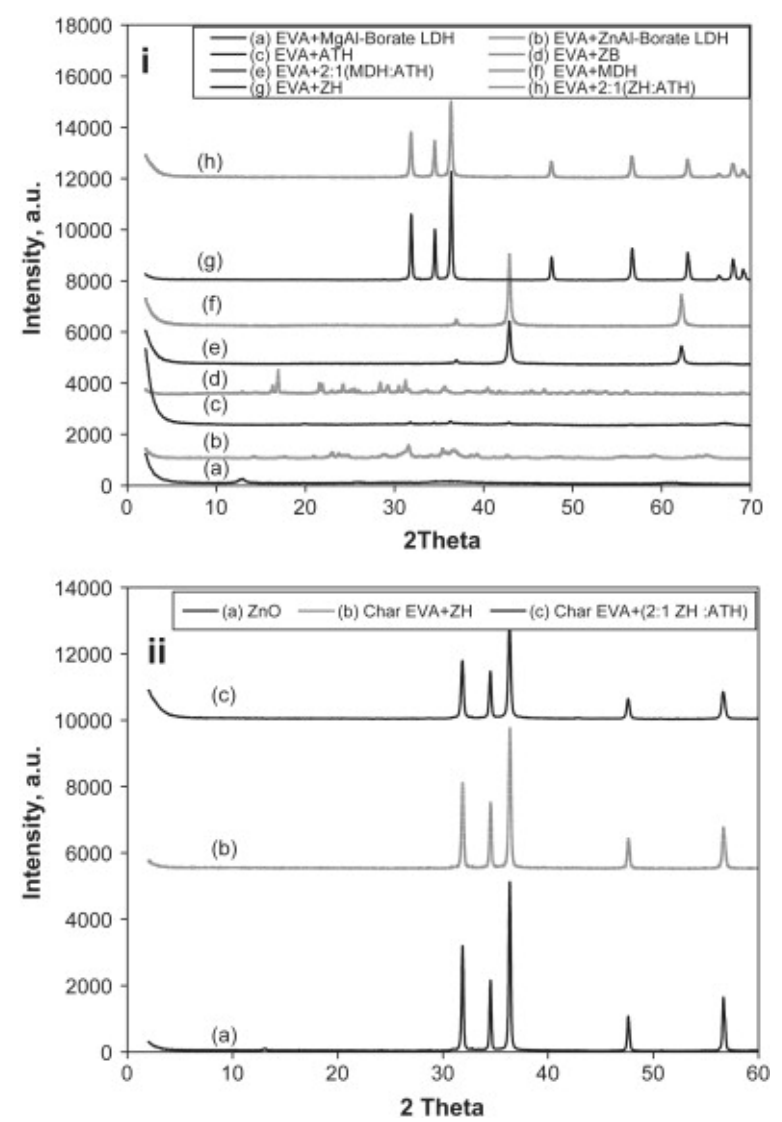

Fig. 7. (i): XRD of residual char (a) EVA + 40\% MgAl-borate LDH, (b) EVA + 40\% ZnAl-borate LDH, (c) EVA + 40\%ATH, (d) EVA + 40\% ZB, (e) EVA + 40\% (2:1 MDH:ATH) (f) EVA + 40\% MDH, (g) EVA + 40\% ZH and (h) EVA+ 40\% (2:1 ZH:ATH) formulations following cone calorimetry test under a heat flux of $35 \mathrm{~kW} / \mathrm{m}^{2}$. (ii): A comparison of XRD traces for (a) zinc oxide, (b) the char for EVA + zinc hydroxide and (c) char for EVA + (2:1 zinc hydroxide + ATH) obtained after cone calorimetry. Ref. ${ }^{[20]}$, pdf = 36-1451 for ZnO.

\section{Conclusions}

Layered double hydroxides intercalated with borate anion were successfully prepared with the metals $\mathrm{Mg}^{2+}, \mathrm{Zn}^{2+}$, and $\mathrm{Al}^{3+}$ using the coprecipitation method. EVA composites prepared using these LDHs showed improved thermal stability. The fire properties of the composites studied using cone calorimetry show that the addition of LDHs reduces the PHRR and AMLR significantly. The reduction in PHRR and AMLR increases with an increase in the loading of the LDHs. At $40 \%$ loading, the reduction in PHHR observed in composites containing LDHs were significantly higher than those consisting of zinc hydroxide, $\mathrm{MDH}$, and their combinations, but was similar to a combination of $\mathrm{MDH}$ and $\mathrm{ATH}$. XRD analyses of the char obtained after cone calorimetry reveal that oxides formed during combustion were amorphous. Only the char composites containing zinc hydroxide was crystalline and this showed the presence of zinc oxide. LDHs are effective flame retardants for EVA and are promising flame retardants for the future.

\section{Acknowledgements}

The authors gratefully thank Dr Jeanne Hossenlopp for helpful discussions. Partial support of this work was provided by US Department of Commerce, National Institute of Standards and Technology, Fire Research Division, under grant number 60NANBD6018. 


\section{References}

[1] G. Zhang, P. Ding, M. Zhang, B. Qu Synergistic effect of layered double hydroxide with hyperfine magnesium hydroxide in halogen-free flame retardant EVA/HFMH/LDH nanocomposites Polym Degrad Stab, 92 (2007), pp. 1715-1720

[2] F. Carpentier, S. Bourbigot, M. Le Bras, R. Delobel, M. Foulon Charring of fire retarded ethylene vinyl acetate copolymer-magnesium hydroxide/zinc borate formulations Polym Degrad Stab, 69 (2000), pp. 83-92

[3] C.-M.J. Jiao, Z. Wang, X. Chen, Y. Hu Synthesis of magnesium/aluminum/iron layered double hydroxide and its flammability characteristics in halogen free, flame retardant ethylene/vinyl acetate copolymer composites J Appl Polym Sci, 107 (2008), pp. 2626-2631

[4] D.A. France, L. Ferry, J.-M.L. Cuesta, A. Crespy Magnesium hydroxide/zinc/talc composites as flameretardants in EVA copolymer Polym Int, 49 (2000), pp. 1101-1105

[5] C.M. Jiao, Z.Z. Wang, Z. Ye, Y. Hu, W.C. Fan Flame retardation of ethylene-vinyl acetate copolymer using nano magnesium hydroxide and nano hydrotalcite J Fire Sci, 24 (2006), pp. 47-64

[6] G. Beyer Flame retardancy of nanocomposites - from research to technical products J Fire Sci, 23 (2005), pp. $75-87$

[7] C. Nyambo, D. Wang, C.A. Wilkie Will layered double hydroxides give nanocomposites with polar or nonpolar polymers? Polym Adv Technol (2008), 10.1002/pat.1272

[8] C. Nyambo, P. Songtipya, E. Manias, M. Jimenez-Gasco, C.A. Wilkie Effect of MgAl-layered double hydroxide exchanged with linear alkyl carboxylates on fire retardancy of PMMA and PS J Mater Chem, 18 (2008), pp. 4827-4838

[9] C. Nyambo, E. Kandare, D. Wang, C. Wilkie Flame-retarded polystyrene: investigating chemical interactions between ammonium polyphosphate and MgAl layered double hydroxide Polym Degrad Stab, 93 (2008), pp. 1656-1663

[10] F. Cavani, F. Trifiro, A. Vaccari Hydrotalcite type anionic clays preparation, properties and applications Catal Today, 11 (1991), pp. 173-301

[11] Shen KK, Ferm DJ. Recent advances on the use of boron compounds as fire retardants: an overview. In: Proceedings of the conference on recent advances in flame retardancy of polymeric materials. Eleventh annual BCC conference on flame retardancy; 2000, 11, p. 213-21.

[12] Shen KK, Ferm DJ. Recent advances in the use of borates as fire retardants. In: Proceedings of the conference on recent advances in flame retardancy of polymeric materials. Applications; 1995, 6, p. 239-47.

[13] S. Bourbigot, F. Carpentier, M. Le Bras, R. Leeuwendal, K.K. Shen, D. Schubert Recent advances in the use of zinc borates in flame retardancy of EVA Polym Degrad Stab, 64 (1999), pp. 419-425

[14] Y. Yang, X. Shi, R. Zhao Flame retardancy behavior of zinc borate J Fire Sci, 17 (1999), pp. 355-361

[15] A. Bhattacharyya, D.B. Hall New triborate pillared hydrotalcites Inorg Chem, 31 (1992), pp. 3869-3870

[16] D. Wang, J. Zhu, Q. Yao, C.A. Wilkie A comparison of various methods for the preparation of polystyrene and poly(methyl methacrylate) clay nanocomposites Chem Mater, 14 (2002), pp. 3837-3843

[17] L. Li, S. Ma, S. Liu, Y. Yue, J. Hui, R. Xu, et al. Synthesis and characterization of tetraborate pillared hydrotalcite Chem Mater, 8 (1996), pp. 204-208

[18] M. Del Arco, C. Gutierrez, C. Martin, V. Rives, J. Rocha Effect of the Mg:Al ratio on the borate (or silicate)/nitrate exchange in the hydrotalcite J Solid State Chem, 68 (2000), pp. 272-280

[19] A. Okada, A. Usuki Twenty years of polymer-clay nanocomposites Macromol Mater Eng, 296 (2006), pp. $1449-1476$

[20] A. Morgan, P. Dubois Polymer-layered silicate nanocomposites: preparation, properties and uses of new class of materials Mater Sci Eng, 28 (2000), pp. 1-63

[21] W. Yang, Y. Kim, P.K.T. Liu, M. Sahimi, T.T. Tsotsis A study by in situ techniques of the thermal evolution of the structure of $\mathrm{Mg}-\mathrm{Al}-\mathrm{CO}_{3}$ layered double hydroxide Chem Eng Sci, 57 (2002), pp. 2945-2953

[22] M. Jakupca, P.K. Dutta Thermal and spectroscopic analysis of a fatty acid-layered double-metal hydroxide and its application as a chromatographic stationary phase Chem Mater (1995), pp. 989-994 
[23] L. Pesic, S. Salipurovic, V. Markovic, D. Vucelic, W. Kagunya, W. Jones Thermal characteristics of a synthetic hydrotalcite-like material J Mater Chem, 2 (1992), pp. 1069-1073

[24] S. Miyata Physico-chemical properties of synthetic hydrotalcite in relation to compositions Clays Clay Miner, 28 (1980), pp. 50-56

[25] R. Vincente Study of layered double hydroxides by thermal methods Layered double hydroxides: present and future, Nova Science Publisher (2001), pp. 115-137

[26] Bourbigot S, Le Bras M. Thermal degradation and combustion mechanism of EVA-magnesium hydroxidezinc borate. In: Nelson GL, Wilkie CA, editors. ACS symposium Series \# 797; 2001. p. 173-85 [chapter 14].

[27] G. Camino, R. Sgobbi, A. Zaopo, S. Colombier, C. Scelza Investigation of flame retardancy in EVA Fire Mater, 24 (2000), pp. 85-90

[28] M.C. Costache, D.D. Jiang, C. Wilkie Thermal degradation of ethylene-vinyl acetate copolymer nanocomposites Polymer, 46 (2005), pp. 6947-6958

[29] A. Riva, M. Zanetti, M. Braglia, G. Camino, L. Falqui Thermal degradation and rheological behaviour of EVA/montmorillonite nanocomposites Polym Degrad Stab, 77 (2002), pp. 299-304

[30] G. Camino, A. Maffezzoli, M. Braglia, D. Lazzaro, M. Zammarano Effect of hydroxides and hydroxycarbonate structure on fire retardant effectiveness and mechanical properties in ethylenevinyl acetate copolymer Polym Degrad Stab, 74 (2001), pp. 457-464

[31] U. Braun, B. Schartel, M. Fichera, C. Jager Flame retardancy mechanisms of aluminum phosphinate in combination with melamine polyphosphate and zinc borate in glass-fibre reinforced polyamide 6,6 Polym Degrad Stab, 92 (2007), pp. 1528-1545

[32] Powder diffraction file alphabetical indexes, inorganic phases JCPDS, International Center for Diffraction Data, Swarthmore, PA (1999)

[33] M.C. Costache, M.J. Heidecker, E. Manias, G. Camino, A. Frache, G. Beyer, et al. The influence of crabon nanotubes, organically-modified montmorillonites and layered double hydroxides on the thermal degradation and fire retardancy of polyethylene, ethylene-vinyl acetate copolymer and polystyrene Polymer, 48 (2007), pp. 6532-6545

[34] C. Manzi-Nshuti, C. Wilkie Ferrocene and ferrocenium modified clays and their styrene and EVA composites Polym Degrad Stab, 92 (2007), pp. 1803-1812 